\title{
Hanging case of an Adult Male: A Case Report
}

\author{
Md. Rafiqul Bari ${ }^{1}$, T. C. Das ${ }^{2}$, Anwar Hussain ${ }^{3}$, Md. Mazharul Islam ${ }^{4}$, Abul Kalam Mohammad Yousuf ${ }^{5}$ \\ ${ }^{I}$ Associate Professor, Dept. of Forensic Medicine, Northern International Medical college (NIMC), Dhaka, ${ }^{2}$ Professor and Head, \\ Dept. of Forensic Medicine, Ad-din Women's Medical College, Dhaka, ${ }^{3}$ Professor and Head, Dept. of Forensic Medicine, NIMC, \\ Dhaka, ${ }^{4}$ Assistant Professor, Dept. of Forensic Medicine, NIMC, ${ }^{5}$ Dhaka, Assistant Professor, Dept. of Pharmacology, NIMC, Dhaka
}

\begin{abstract}
In case of hanging the process of respiration i.e. the exchange of air between the atmosphere and the alveoli of lungs is prevented by ligature in neck, leading to asphyxia and death.Hanging may be complete/incomplete (partial) where the constricting forces are the body weight or even only the weight of the head.In complete hanging whole body is suspended, no part of the body touches the ground. Complete hanging is suicidal in nature unless otherwise proved.In partial hanging any part of the body touches the ground. Partial hanging is suicidal $(\mathbf{1 0 0 \%})$ in nature \& there is no 2 nd thought.Generally Medical and non-medical personals think that complete hanging may be suicidal, but partial hanging is definitely homicidal in nature which is not the actual fact.Hanging with signs of torture in various parts of body goes in favour of (provoked) suicidal nature.
\end{abstract}

\section{Introduction}

In police custodial death everybody 1 st consider it as a homicidal ( by torture) death, which may be true or may not be \& should be proved and established by proper scientifically based investigation. Such as an excessive amount of external and/or internal neck injury, possibly with a fracture of the cricoid cartilage, which is distinctly uncommon from a hanging. There may also be defensive type of injuries, or an inconsistent pattern of lividity. The investigative and autopsy information may reflect strangled person who was subsequently placed into a hanging position to simulate a suicide, or a person who was intentionally hanged, perhaps after he had become subdued from ethanol or drug toxicity ${ }^{1}$. A case .of hanging happened in Motijheel PS on 16. 10. 96. and investigation was done accordingly.

\section{Case Report:}

The case is presented as follows. Sohel Mahmud (Tuhin)'s dead body was found hanged by ligature in neck in a washroom at the Motijheel Police Station. As the death happened in police custody, the inquest and chalan was prepared and submitted for autopsy by metropolitan magistrate Mr. Rezaul Qader. The ligature material used was nylon shoe lace.Autopsy was done by a three member medical board. Histopathological examination of soft tissue under ligature mark was done. Chemical examination of viscera was also done. The medical board gave opinion in favour of antemortem hanging which was suicidal in nature.

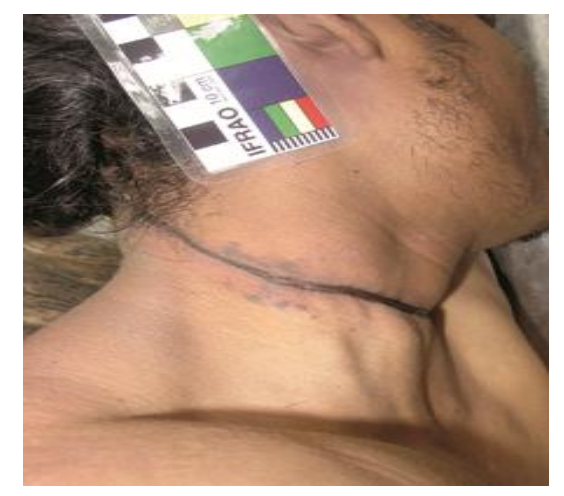

Figure-1: Ligature mark of ante-mortem suicidal Hanging Autopsy of dead body of Mr. Sohel Mahmud (Tuhin), aged 22yrs. was done on 18.10 .96 at DMC mortuary by a three members medical board.The external examination was done by naked eyes. Internal examination was also done by naked eyes.

The body was dissected by two incisions:---

1. One modified $\mathrm{Y}$ incision coveringthe neck, chest \& abdomen.

2. A transverse incision on scalp.

The aim was to open \& examine the 3 cavities containing the vital \& other organs. The viscera were examined by naked eyes. On examination sign of central cyanosis was found \& the lungs, trachea, brain \& other viscera were found congested.

One $1 / 2$ inch wide ligature mark was found in upper part of neck which was oblique \& non-continuous with a gap of about 2inch in left back side of neck. The skin at ligature site was parchmentised.There was dribbling of saliva from right angle of mouth to chest. No other external or internal injury was found.In a typical hanging, the knot of the ligature should be at the back side of the nape of neck . Typical hanging is not very common in occurrence ${ }^{2}$. 
J. Dhaka National Med. Coll. Hos. 2012; 18 (01): 63-64 Subcutaneous tissue was sent to DMC pathology dept. for histopathological examination \& viscera were sent to chemical examiner of CID for chemical examination.

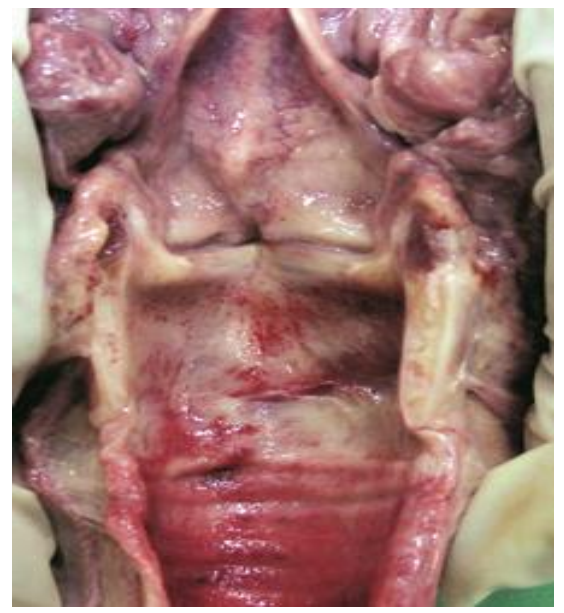

Figure-2: Congestion of trachea

Histopathological report date 31.10 .96 reveals that tissues from the submitted material show areas of viable \& necrotic skeletal muscle along with fibrous tissue with scanty infiltration of inflammatory cells \& areas of haemosiderin pigments.

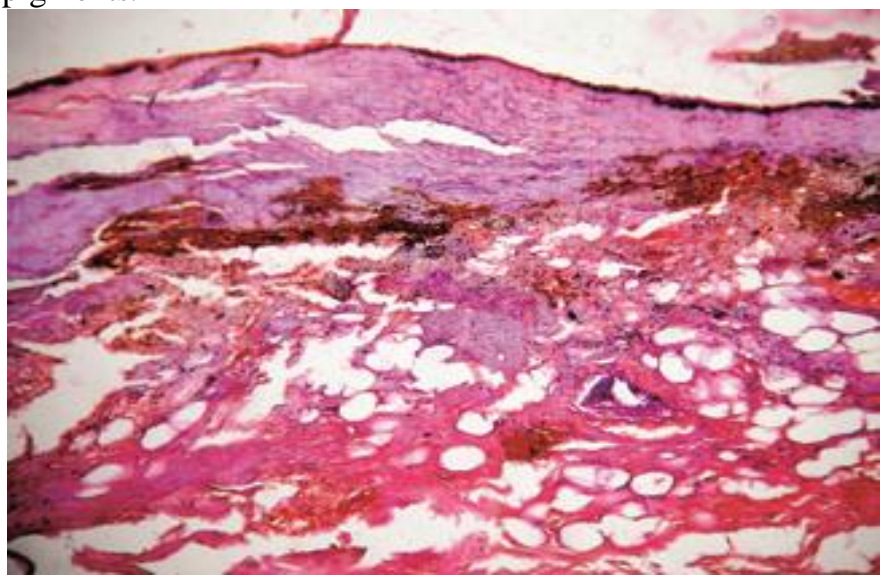

Figure-3: Histological findings of soft tissues under ligature mark

Chemical examination report of viscera date 2.11.96 stated that no poison is found in the preserved viscera.

After getting the histo-pathological and chemical examination reports the medical board agreed to submit the following opinion------

*Considering post mortem examination findings, histopathological and chemical reports we are of the opinion that the death was due to asphyxia resulting from hanging which was ante-mortem \& suicidal in nature.

\section{Discussion:}

Complete hanging is considered as suicidal in nature, (Whatever the site of occurance ) unless otherwise proved. Partial hanging is considered as suicidal, there is no 2 nd thought. In this case it was a case of complete hanging and the ligature material used was two pieces of nylon shoe lace which raised confusion that how hanging can be caused by shoe lace. But it is quite possible. It may be mentioned that hanging may be done even by a sacred thread ${ }^{3}$.

Following ante-mortem signs of hanging were present: ---1. Dribbling of saliva from right angle of mouth upon the right chest.

2. Presence of parchmentisation of skin at the ligature site.

3. Presence of inflammatory cells in subcutaneous tissue under the ligature site.

4. Signs of central cyanosisn and, all viscera were congested.

Above 4 ante-mortem findings are in favor of ante-mortem and suicidal in nature.

In case of post mortem hanging--- no ante-mortem sign is found and cause or causes other than hanging should be present in the dead body which has caused the death of the person.

Homicidal hanging is rare. It is not ordinarily possible with an adult victim, if he is not intoxicated or made unconscious by some other means, like head injury. Alternatively, the victim is either a child or a very debilitated person. Usually the rope is first fastened around the neck and then it is pulled over a high point of suspension. Hence, there will be presence of evidence of pulling or dragging of the victim on the ground as also presence of evidence of friction at the point of suspension, with the ligature material. Signs of struggle may be present on the body of the victim and at the place ${ }^{4}$.

\section{Conclusion:}

Hanging is most frequently observed since it is commonly chosen as a method of suicide. Considering thorough complete autopsy including both external and internal examination, chemical and histopathological examination reveals this case as a true complete suicidal hanging, there is no option of second thought. So in conclusion, it can be stated that 'Hanging is always suicidal unless otherwise proved'.

\section{Reference:}

1. Dolinak D, Matshes E, Lew E. Forensic Pathology, Principles and Practice, $1^{\text {st }}$ edition. 2005; p-214.

2. Nandy- A. Principles of Forensic Medicine including Toxicology, Violent asphyxial deaths, 1st edition. 1995; p-320.

3. Reddy KSN. The essentials of Forensic Medicine and Toxicology, Mechanical Asphyxia, $26^{\text {th }}$ edition. 2007; p-296.

4. Nandy A. Principles of Forensic Medicine Including Toxicology, Violent asphyxial deaths, 3rd edition. 2010; p-523. 